\title{
Noncoal Contractor Mining Facts - 2003
}

The Mine Safety and Health Administration (MSHA) defines an independent contractor as "any person, partnership, corporation, subsidiary of a corporation, firm, association or other organization that contracts to perform services or construction at a mine." Contractors that perform specific types of work are required to report the number of employees who perform work at coal mines and at noncoal mines.

1. In 2003, a total of 3,989 contracting companies reported employment at noncoal mines (metal, nonmetal, sand and gravel, and stone mines) to MSHA.

2. A total of 39,183 noncoal contractor employees, corresponding to 18,871 full-time equivalent (FTE) employees, were reported to MSHA in 2003. ${ }^{1}$ This is an increase of $1.8 \%$ in FTE noncoal contractor employees from 2002.

- The highest proportion of noncoal contractor employees was found in surface production operations (65.6\%), followed by processing mills (30.5\%) and underground operations $(3.9 \%)^{2}$

3. Four work-related fatalities occurred among noncoal contractor employees in 2003, compared to six in 2002.

- In 2003, noncoal contractor employees had a fatality rate of 21.2 per 100,000 FTE employees.

- Two fatalities occurred in surface work locations (fatality rate $=16.2$ per 100,000 FTEs), and two occurred in preparation plants or mills (fatality rate $=34.8$ per 100,000 FTEs).

4. There were 257 nonfatal lost-time injuries among noncoal contractor employees, occurring at a rate of 1.4 per 100 FTE employees in 2003. A total of 15,213 days lost from work resulted from these injuries. ${ }^{3}$

- For noncoal contractor employees, the median number of days lost from work as a result of nonfatal lost-time injuries was 24. The median number of days lost from work for noncoal operator employees was 15 days.

- The injury rate among noncoal contractor employees in underground operations was 2.3 per 100 FTE employees, compared to 1.9 in processing mills/preparation plants and 1.1 in surface mining operations.

- The most frequently reported types of accidents among noncoal contractor employees were handling material $(n=91 ; 35.4 \%)$ and slips or falls $(n=61 ; 23.7 \%)$.

- Of the most frequently reported injuries (greater than $10 \%$ of total), the most severe injuries (as measured by the median number of days lost from work) were associated with fractures and chips (median = 51 days: $n=49)$.

- The back ( $n=45 ; 17.5 \%$ ) was the most frequently reported part of body injured, accounting for 2,669 days lost from work. ${ }^{4}$ Injuries to the finger were also frequently reported $(n=33 ; 12.8 \%)$, and accounted for 1,474 days lost from work.

- Among noncoal contractor employees, those with the MSHA job title of "mechanic/repairman/helper" had the greatest number of nonfatal lost-time injuries $(n=41 ; 16.0 \%)$, followed by those with a job title of "truck driver" $(n=32 ; 12.5 \%)$ and "laborer/utility man/bull gang" ( $n=29 ; 11.3 \%)$.

5. Twelve cases of occupational illness in noncoal contractor employees were reported to MSHA in $2003 .{ }^{5}$ There were five cases of heat/sunstroke; two cases each of hearing loss or impairment and joint, tendon, muscle inflammation or irritation; and one case each of asphyxia, noncontact electric burn, and an unclassified occupational disease.

Note: All analyses exclude office employees.

${ }^{1}$ Computed using reported employee hours (2,000 hours $\left.=1 \mathrm{FTE}\right)$.

${ }^{2}$ Surface production operations include strip mines, surface operations at underground mines, preparation plants, mills, auger mining, culm banks, dredge, and surface shops and yards.

${ }^{3}$ Includes actual days away from work and/or days of restricted work activity. For permanently disabling injuries only, statutory days charged by MSHA were used if they exceeded the total lost workdays.

${ }^{4}$ MSHA only reports the most severely injured part of body for accidents involving injury to multiple body parts.

${ }^{5}$ Because of the complexity of attributing disease causation to the workplace, occupational illnesses may be underreported. 


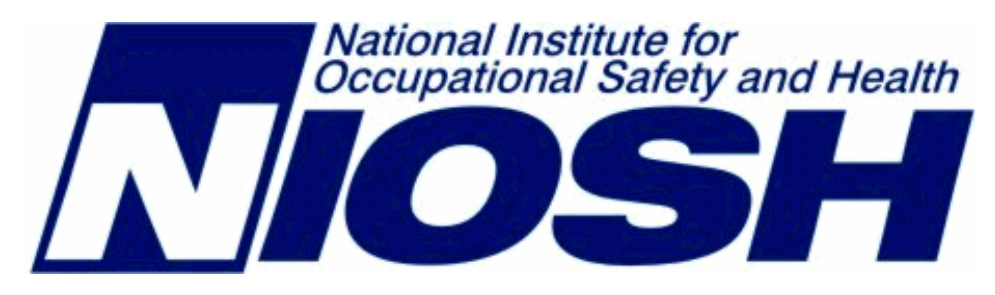

Delivering on the Nation's promise:

Safety and health at work for all people through research and prevention

For information about occupational safety and health topics contact NIOSH at:

1-800-35-NIOSH (1-800-356-4674)

Fax: 513-533-8573

e-mail: pubstaft@cdc.gov

www.cdc.gov/niosh

\section{SAFER • HEALTHIER • PEOPLE ${ }^{T M}$}

